\title{
PROSES CORPORATE REBRANDING PJTV BANDUNG MENJADI SKTV
}

\author{
Yuliyanti Sholihat ${ }^{1}$, Susie Perbawasari ${ }^{2}$, Syauqy Lukman $^{3}$ \\ ${ }^{1}$ Magang Penmas Polda Jabar \\ ${ }^{2,3}$ Program Studi Hubungan Masyarakat, Fakultas Ilmu Komunikasi, Universitas Padjadjaran
}

\begin{abstract}
ABSTRAK
Tujuan penelitian ini adalah untuk mengetahui bagaimana tahapan analisis, perencanaan, implementasi, dan evaluasi proses corporate rebranding PJTV Bandung menjadi SKTV. Paradigma yang digunakan adalah paradigma positivisme, jenis studi deskriptif, dan menggunakan pendekatan kualitatif. Teknik pengumpulan data dilakukan melalui wawancara, observasi, dan studi pustaka. Penelitian ini dilakukan di kantor SKTV yang berada di Gedung Lucky Square Lt.1 Blok A2-05, Jl. Terusan Jakarta No. 2 Bandung. Berdasarkan hasil penelitian menunjuka bahwa SKTV dalam melakukan proses rebranding melalui empat tahap. Pertama, tahapan analisis dilakukan dengan menganalisis faktor-faktor pendorong proses rebranding. Kedua, tahap perencanaan yang dilakukan dengan mengubah target audience, mengganti nama PJTV Bandung menjadi SKTV, menganti atribut visual, dan melakukan pergantian kepala departemen yang terjadi pada struktur organisasi SKTV. Ketiga tahap implementasi yang terdiri dari sub fase relaunching untuk internal dengan mengadakan syukuran dan gathering bersama seluruh karyawan dan relaunching untuk eksternal dengan membuat promosi di berbagai media, serta membuat talkshow budaya yang mengundang berbagai pihak eksternal perusahaan. Keempat, tahap evaluasi dilakukan dengan mengadakan meeting dan kordinasi di setiap departemen. Simpulan dari penelitian ini adalah proses corporate rebranding yang dilakukan oleh SKTV sudah baik, namun belum maksimal dalam tahap analisis, dan evaluasi karena SKTV belum melakukan penelitian yang dilakukan secara langsung untuk mengetahui tanggapan target audience baik sebelum maupun sesudah rebranding.
\end{abstract}

Kata-kata Kunci: Brand; Branding; Rebranding; Repositioning; Televisi Lokal

\section{CORPORATE REBRANDING PROCESS OF PJTV BANDUNG TO BE SKTV}

\begin{abstract}
The purpose of this research is to find out the analysis stages, planning, implementation, and evaluation of the corporate rebranding process of PJTV Bandung into SKTV. The paradigm used in this research is positivism, with descriptive study type, and also uses qualitative approach. The data collecting technic was done through interview, observation, and literature review. This research was done on SKTV office which is located in Lucky Square Building Lv. 1 Block A2-05, Jl. Terusan Jakarta No. 2 Bandung. According to the result of the research, it shows that SKTV had done the rebranding process in four stages. First, analysis stage done by analyzing the supporting factors for the rebranding process. Second, the planning stage done by changing the audience target, changing the name from PJTV into SKTV, changing the visual attributes, and performing the changing of the department leader in the organization structure of SKTV. Third, implementation stage which is consisted of relaunching sub phase for the internals by holding a celebration and a gathering with all employees and relaunching for the externals by creating promotions in various media, also exercising a cultural talk show which invites various external parties. Fourth, evaluation stage done by holding a meeting and coordination in each department. The conclusion of this research is that the corporate rebranding process of SKTV has been done well, but not maximized yet in the analysis, and evaluation stage because SKTV has not performed any study yet to find out the response of the audience target both before and after the rebranding.
\end{abstract}

Keywords: Brand; Branding; Local Television; Rebranding; Repositioning

Korespondensi: Yuliyanti Sholihat. Magang Penmas Polda Jabar. Jl. Soekarno-Hatta 748 Kota Bandung. Email: yuliyantisholihat.yy@gmail.com 


\section{PENDAHULUAN}

Televisi masih menjadi salah satu media yang dipilih oleh masyarakat. Seluruh stasiun televisi free-to-air di Indonesia dapat ditangkap dengan menggunakan antena UHF/VHF (terestrial) sehingga memudahkan masyarakat untuk mengakses informasi maupun hiburan dari televisi. Namun berlakunya Undangundang Nomer 23 Tahun 2002 tentang Penyiaran, izin penyelenggaraan siaran melalui antena UHF/VHF (terestrial) yang dikeluarkan hanyalah untuk stasiun televisi lokal. Adanya pertumbuhan industri televisi di Indonesia melahirkan banyak stasiun televisi lokal di daerah. Televisi lokal membawa harapan tidak hanya di bidang pertelevisian saja, namun juga berpengaruh pada tersedianya lapangan kerja bagi masyarakat dan juga kemajuan daerah. Hingga saat ini televisi lokal masih terus berkembang di berbagai daerah, salah satunya di daerah Bandung.

PT. ESA VISUAL PADJADJARAN TIVI merupakan perusahaan yang menaungi Padjadjaran TV (PJTV), merupakan salah satu stasiun televisi lokal pertama di kota Bandung yang didirikan pada tahun 2005. Pada 15 April 2010, Padjadjaran TV berganti nama menjadi Parijz van Java TV yang menjangkau tontonan bagi keluarga masyarakat Bandung. Parijz van Java TV kembali mengalami perubahan nama, namun kali ini cukup berbeda. Parijz van Java TV (PJTV) berganti nama menjadi Sunda Kiwari TV (SKTV). Pergantian nama tersebut ditandai dengan acara dialog budaya "Sunda Kiwari Dalam Perspektif Indonesia" yang disiarakan langsung dari Hotel Mason Pine and Resort Kota Baru Parahyangan Bandung Barat. Nama SKTV merupakan transformasi lima televisi konvensional milik Jawa Pos yang berada di wilayah Jawa Barat, yaitu PJTV Bandung, Sumedang Televisi (SMTV), Televisi Kuningan (TVK), Jatiwangi Televisi, dan CB Chanel Cianjur.

Berdiri sejak tahun 2005 dengan kekuatan pemancar $3 \mathrm{kw}$, Padjadjaran TV atau PJTV Bandung merupakan salah satu televisi lokal pertama di Bandung. Diawal kemunculannya, PJTV Bandung memilih family program sebagai tayangan utamanya. PJTV Bandung memilih target pemirsa dengan segmen kelas B-C-D atau menengah kebawah, yaitu sebagai primary target adalah keluarga dengan usia 10-55 tahun dan secondary target yaitu remaja dengan usia 15-25 tahun. Pada tahun 2010, Padjadjaran TV bertanspormasi menjadi Parijz van Java TV. Target pemirsa mengalami perubahan dari penonton kelas B-C$\mathrm{D}$ atau kelas menengah kebawah menjadi kelas A yaitu kelas atas. Dengan adanya perubahan tesebut diharapkan PJTV Bandung menjadi televisi pilihan utama penonton yang mampu merangkul semua kalangan.

Ada beberapa alasan mengapa PJTV melakukan rebranding menjadi SKTV seperti keinginan manajemen serta adanya perbedaan antara target audience yang telah ditetapkan dengan keadaan sebenarnya dilapangan. Dalam melakukan proses rebranding PJTV Bandung menjadi SKTV ada tim khusus yaitu, tim kreatif. Perubahan tidak hanya terjadi pada 
nama saja, banyak aspek yang ikut berubah seperti logo, slogan, visi-misi, program acara, target audience hingga pergantian orang-orang yang ada pada struktur organisasi. Adapun cara yang dilakukan pihak SKTV untuk memperkenalkan nama baru serta mempertahankan pemirsa setia PJTV Bandung adalah dengan membuat promo baik secara off air maupun on air. Program unggulan yang ada di SKTV salah satunya Warta Kiwari.

Dalam proses corporate rebranding PJTV Bandung menjadi SKTV, PT. ESA VISUAL PADJADJARAN TIVI telah melakukan tahap-tahap sesuai dengan konsep yang dikemukakan oleh Mari Ahonen (2008). Dalam konsep tersebut (Ahonen, 2008) terdapat tahap analisis, perencanaan, implementasi, dan evaluasi, termasuk sub fase yang ada dalam tahap-tahap tersebut telah dilaksanakan oleh PJTV Bandung hingga kini akhirnya berganti nama menjadi SKTV. Peneliti menggunakan jurnal dari Mari Ahonen (2008) sebagai dasar penyusunan penelitian.

\section{TINJAUAN PUSTAKA}

Faktor-faktor sebagai motivasi utama perusahaan melakukan rebranding menurut Tjiptono, dkk. (2008), yaitu:(1) 'Menyegarkan kembali' atau memperbaiki citra merek, (2) Memulihkan citra setelah terjadinya krisis atau skandal, (3) Bagian dari marger atau akuisisi, (4) Bagian dari de-marger atau spin-off, (5) Mengharmonisasikan merek di pasar internasional, (6) Merasionalisasi portofolio merek, dan (7) Mendukung arah strategik baru perusahaan (Tjiptono, Chandra, \& Adrian, 2008).

Terkait dengan reposisi brand, Cheryl Isen (2012) mengungkapkan 6 alasan untuk mereposisi suatu brand, yaitu: (1) Kompetitor sudah merebut positioning brand kita, (2) Positioning brand awal menjadi membingungkan, (3) Perusahaan beruansa baru dengan keunggulan kompetitif yang eksklusif, (4) Adanya perubahan strategi perusahaan dalam lini bisnis seperti akuisisi atau pengembagan dengan target market baru, (5) Kompetitor berusaha mengubah permainan, perubahan tren tidak bisa dihindari, (6) Adanya perubahan yang signifikan pada struktur perusahaan (Isen, 2010). Lebih lanjut, dalam jurnal Muzellec, et. al. (2003) klasifikasi renaming terbagi menjadi tiga bagian yaitu: (1) Nama deskriptif, (2) Nama asosiatif atau sugestif, (3) Berdiri sendiri, nama abstraksi, atau diciptakan (Muzellec, Doogan, \& Lambkin, 2003).

\section{METODE PENELITIAN}

Dalam penelitian ini peneliti menggunakan paradigma positivisme. Menurut Salim (2006), keyakinan dasar aliran ini berakar pada paham ontology realism yang menyatakan bahwa realitas berada (exist) dalam kenyataan dan berjalan sesuai dengan hukum alam (natural laws) (Salim, 2006). Penelitian deskriptif bertujuan untuk memaparkan siatuasi atau peristiwa. Penelitian deskriptif ini tidak bertujuan untuk mencari ataupun menjelaskan hubungan, serta tidak menguji hipotesis ataupun membuat prediksi. Metode deskriptif 
menitikberatkan pada observasi dan suasana alamiah. Dalam hal ini peneliti bertindak sebagai pengamat. Seperti penjelasan Rakhmat (2012) mengenai metode deskriptif, bahwa peneliti tidak berusaha untuk memanipulasi variabel. Karena kehadirannya mungkin mempengaruhi perilaku gejala (reactive measures), peneliti berusaha memperkecil pengaruh ini. Penelitian sosial telah menghasilkan beberapa pengukuhan yang tidak terlalu banyak "merusak" kenormalan (unobstrusive measeres) (Rakhmat, 2012).

Pada penelitian ini, peneliti memilih teknik purposive sampling. Penentuan sumber data pada orang yang akan diwawancarai dilakukan dengan secara purposive, yaitu dipilih dengan pertimbangan dan tujuan tertentu (Sugiyono, 2010). Teknik pengumpulan data dalam penelitian ini ada tiga yaitu wawancara, observasi dan studi pustaka. Esterberg (2002) mengemukakan beberapa macam wawancara yaitu wawancara terstruktur, semiterstruktur, dan tidak terstruktur. Dalam penelitian ini, peneliti menggunakan wawancara semiterstruktur dengan wawancara individu dengan individu (Sugiyono, 2010). Menurut Sanafiah Faisal (1990), observasi diklarifikasikan menjadi observasi berpartisipasi (participant observation), observasi secara terang-terangan dan tersamar (overt observation dan covert observation), dan observasi yang tak berstuktur (unstructured observation) (Sugiyono, 2010). Peneliti menggunakan teknik observasi secara terangterangan dan tersamar. Dalam pengumpulan data, peneliti menyatakan secara terus terang kepada narasumber bahwa sedang melakukan penelitian. Observasi dilakukan di kantor SKTV. Studi pustaka yang dilakukan oleh peneliti adalah dengan mempelajari dokumen seperti data-data yang didapatkan dari pihak SKTV, mempelajari buku-buku, skripsi serta jurnal yang berkaitan dengan penelitian ini.

Dalam penelitian kualitatif, analisis data dilakukan sejak sebelum memasuki lapangan, selama dilapangan, dan setelah di lapangan (Sugiyono, 2010). Penelitian ini menggunakan teknik analisis data berdasarkan model Miles dan Huberman (1984) yaitu reduksi data, penyajian data, dan penarikan kesimpulan (Sugiyono, 2010). Pertama, reduksi data. Data yang diperoleh dari lapangan jumlahnya cukup banyak, untuk itu maka perlu dicatat secara teliti dan rinci. Peneliti memaparkan hasil penelitian dengan mempertajam analisis sehingga memudahkan pengambilan hasil proses corporate rebranding PJTV Bandung menjadi SKTV. Kedua, penyajian data. Setelah data direduksi, langkah selanjutnya adalah mendisplay data. Dalam penelitian ini, peneliti mengumpulkan data berupa informasi melalui wawancara, observasi dan studi pustaka secara bertahap, lalu mereduksi, mengelompokkan, hingga memberikan interpretasi pada data yang telah didapatkan. Ketiga, penarikan kesimpulan. Kesimpulan awal yang akan dikemukakan masih bersifat sementara, dan akan berubah bila tidak ditemukan bukti-bukti yang kuat yang mendukung pada tahap pengumpulan data berikutnya. Peneliti menarik kesimpulan dari 
data yang diperoleh dengan mengumpulkan data, memilih data, menguraikan data dan lalu diakhiri dengan penarikan kesimpulan.

Pada penelitian ini peneliti menggunakan teknik validasi data triangulasi. Triangulasi dalam pengujian kredibilitas ini diartikan sebagai pengecekan data dari berbagai sumber dengan cara, dan berbagai waktu. Triangulasi terbagi menjadi Triangulasi sumber, triangulasi teknik pengumupulan data, dan waktu (Sugiyono, 2010). Dalam penelitian ini akan menggunakan triangulasi sumber untuk memeriksa keabsahan data dari responden. Triangulasi sumber menurut Patton, berarti disini peneliti membandingkan dan mengecek balik derajat keterpercayaan suatu informasi yang diperoleh melalui waktu dan alat yang berbeda dalam metode kualitatif (Moleong, 2007).

Dalam penelitian ini, untuk pengumpulan data, peneliti bertemu dengan narasumber untuk wawancara di beberapa tempat di Bandung, termasuk dikantor SKTV Bandung. Untuk waktu penelitian dari bulan Januari-Juni 2018. Dalam hal ini, subyek penelitian adalah orang-orang yang bergabung dalam tim kreatif rebranding PJTV menjadi Sunda Kiwari TV (SKTV). Obyek dalam penelitian ini adalah proses corporate rebranding PJTV Bandung menjadi SKTV. Adapun dari proses rebranding ini terdapat beberapa perubahan seperti nama, logo, slogan, program, dan segmentasi pemirsa dari PJTV Bandung menjadi SKTV. Selain itu juga ada penerapan logo baru seperti pada studio dan beberapa fasilitas kantor yang menunjukan bahwa PJTV Bandung sudah sudah berubah menjadi SKTV.

\section{HASIL DAN PEMBAHASAN}

Tahap analisis merupakan tahap dimana terdapat latar belakang mengapa proses corporate rebranding ini terjadi. Analisis merupakan tahap pertama dalam mengambil keputusan terjadinya proses corporate rebranding PJTV Bandung menjadi SKTV. Latar belakang utama terjadinya corporate rebranding PJTV Bandung menjadi SKTV adalah adanya perbedaan antara target audience yang ditetapkan dengan keadaan sebenarnya dilapangan. Analisis dalam proses corporate rebranding dilakukan oleh perusahaan ketika ada faktor pemicu yang mendorong terjadinya perubahan dalam brand perusahaan. Faktor pemicu tersebut bisa muncul dari dalam perusahaan maupun dari luar perusahaan. PJTV Bandung melakukan analisis sebelum akhirnya memutuskan untuk melakukan proses corporate rebranding menjadi SKTV.

PJTV Bandung memiliki coverage area di wilayah kota Bandung dengan segmentasi urban yang lebih ditunjukan kepada anak muda. Target audience dari PJTV Bandung adalah masyarakat dengan status ekonomi sosial A-B$\mathrm{C}$ atau masyarakat menengah keatas. Namun, berdasarkan hasil AC Nielsen yang dimiliki pihak PJTV Bandung, pemirsa PJTV Bandung justru kebih banyak di daerah pinggiran kota Bandung. Dari hasil Ac Nielsen tersebut diketahui bahwa penonton sebenarnya dari PJTV Bandung adalah masyarakat yang bukan 
berasal dari Kota Bandung seperti Pangalengan, daerah Kabupaten Bandung, dan Ciwidey.

PJTV Bandung merupakan TV lokal dengan jangkauan siaran yang berpusat di Bandung. Sebelum terjadinya proses rebranding yang dilakukan PJTV Bandung menjadi SKTV tentu ada faktor pendorong yang menjadi alasan perubahan tersebut terjadi baik secara internal maupun eksternal. Dengan bergabungnya PJTV Bandung dengan keempat TV lokal lainnya membuat bisnis goals dari penggabungan tesebut adalah wilayah Jawa Barat. Coverage area dan target audience pun ikut berubah.

Kebijakan manajemen ingin menyatukan satu nama TV lokal untuk satu provinsi menjadi salah satu faktor internal. Dengan nama tersebut diharapkan bisa menjadi lebih kuat dalam menjangkau seluruh daerah Jawa Barat. Dengan menyatukan TV-TV lokal tersebut maka coverage area siaran akan semakin luas menuju Jawa Barat walaupun belum secara keseluruhan. PJTV Bandung, SMTV Sumedang, K TV Kuningan, CB Chanel Cianjur, dan Jatiwangi TV Majalengka bergabung menjadi satu dengan nama SKTV. Dalam hal ini PJTV Bandung menjadi kantor pusat dari segala aktifitas yang ada di SKTV, sedangkan keempat TV lokal lainnya menjadi biro.

Untuk faktor pendorong secara eksternal, disadari bahwa orang-orang yang tinggal di kota, terutama yang bekerja tidak menjadikan TV sebagai media hiburannya dan lebih memilih Youtube. Televisi masih menjadi hiburan utama bagi orang-orang yang memiliki waktu luang, terutama didaerah pinggiran kota yang hanya memiliki satu televisi dalam satu rumah. Dengan adanya hal tersebut, pendekatan kultural menjadi pilihan untuk di terapkan dalam perubahan PJTV Bandung menjadi SKTV.

Faktor-faktor sebagai motivasi utama perusahaan melakukan rebranding menurut Tjiptono, dkk. (2008: 374), yaitu:(1) 'Menyegarkan kembali' atau memperbaiki citra merek, (2) Memulihkan citra setelah terjadinya krisis atau skandal, (3) Bagian dari marger atau akuisisi, (4) Bagian dari de-marger atau spin-off, (5) Mengharmonisasikan merek di pasar internasional, (6) Merasionalisasi portofolio merek, dan (7) Mendukung arah strategik baru perusahaan (Tjiptono et al., 2008). Dari tujuh faktor tersebut, faktor yang membuat SKTV memutuskan untuk melakukan rebranding antara lain merger atau penggabungan lima TV konvensional milik Jawa Pos yaitu, PJTV Bandung, SM TV Sumedang, CB Chanel Cianjur, K TV Kuningan, dan Jatiwangi TV Majalengka. Selain itu, rebranding yang dilakukan merupakan bentuk dukungan terhadap strategik baru perusahaan. Jika PJTV Bandung memiliki coverage area di wilayah kota Bandung, maka dengan rebranding menjadi SKTV coverage area yang diharapkan adalah seluruh wilayah Jawa Barat.

PJTV Bandung merupakan TV lokal Bandung yang berdiri hampir 13 tahun lamanya. Tidak banyak TV lokal yang dapat bertahan dalam kurun waktu yang lama. Dalam 
persaingan antar TV lokal yang ada di Bandung tidak dipengaruhi oleh poistioning dari TV lokal yang ada. Persaingan tetap terjadi dengan TV lokal denga positioning berbeda. PJTV Bandung sendiri merupakan TV lokal Bandung yang konsentrasi dengan segmentasi anak mudanya. Sebelum melakukan rebranding, PJTV Bandung pun mengalami persaingan dengan TV lokal Bandung lainnya. Salah satu TV lokal Bandung yang menjadi saingan dari PJTV Bandung adalah Bandung TV dan AK TV.

Adanya televisi lokal erat kaitannya dengan UU No. 32 tahun 2002 tentang Penyiaran, pasal 31 (Effendy, 2008). Dengan adanya perkembangan TV lokal di daerah ini juga tentu membuka lapangan kerja bagi masyarakat setempat. Hal tersebut juga berlaku bagi PJTV Bandung, jangakauan yang semakin luas juga membuka lapangan kerja bagi masyarakat khususnya masyarakat Jawa Barat. Namun dalam kenyataanya sulit menegaskan batasan jangkauan siaran antara TV swasta nasional dan TV lokal. TV swasta nasional memiliki jangkauan siaran yang sangat luas tentu menjadi saingan berat bagi TV lokal.

Penyelenggaraan PJTV Bandung yang melakukan rebranding menjadi SKTV sebagai TV lokal juga berkaitan dengan Peraturan Pemerintah No. 50 tahun 2005 tentang Penyelenggaraan Penyiaran Lembaga Penyiaran Swasta (PP Lembaga Penyaiaran Swasta) bagian ketiga (Jasa Penyiaran Televisi) pasal 36 ayat (e) dan (f) (Effendy, 2008). PJTV Bandung melayani wilayah siaran di Bandung Raya termasuk kota Bandung, Kabupaten
Bandung, Kabupaten Bandung Barat, Cimahi. Dengan adanya proses rebranding PJTV Bandung menjadi SKTV maka wilayah siaran menjadi lebih luas, mencangkup setengah wilayah di Jawa Barat. Dengan demikian, pesaing dari SKTV pun menjadi semakin luas mengikuti luasnya jangkauan siaran yang dimiliki saat ini. Hal tersebut tidak menutup kemungkinan bahwa SKTV sebagai televisi lokal akan berubah menjadi televisi swasta nasional pada beberapa tahun kedepan.

Dengan adanya proses rebranding tersebut tentu ada sesuatu yang ingin dibentuk sebagai bagian dari proses rebranding dari PJTV Bandung menjadi SKTV. Image menjadi salah satu hal yang ingin dibentuk dari proses rebranding ini karena PJTV Bandung berbeda dengan SKTV sekarang ini. Proses rebranding PJTV Bandung menjadi SKTV merupakan upgrade unsur-unsur yang ada di PJTV Bandung tidak menghilang begitu saja. Ciri khas PJTV Bandung masih ada agar orang yang melihat tidak terlalu terkejut melihat perubahan yang terjadi. Dengan nama SKTV, image yang ingin ditampilkan adalah TV dengan jangkauan siaran Jawa Barat dengan pendekatan kultur budaya sunda yang dikemas lebih menarik dan kekinian. Semangat dalam membentuk image tersebut terlihat dari program yang dihadirkan SKTV seperti menghadirkan kembali berita berbahasa Sunda, dan mengangkat icon-icon Jawa Barat dalam program siarannya. SKTV ingin meyakinkan publiknya bahwa budaya dapat mempersatukan persaudaraan.

Selanjutnya adalah penjelasan mengenai proses perencanaan dalam proses corporate 
rebranding PJTV Bandung menjadi SKTV yang terdiri dari repositioning, renaming, redesigning, dan restructuring.

Tahap repositioning ini merupakan tahap dimana PJTV Bandung memposisikan identitas brand barunya sebagai SKTV agar bisa diterima di masyarakat. Repositioning yang dilakukan SKTV yaitu perubahan identitas brand, serta adanya perubahan segmentasi pemirsa dan perluasan coverage area siaran. Faktor utama dari proses corporate rebranding PJTV Bandung menjadi SKTV adalah bagian dari marger dan juga mendukung arah strategik baru perusahaan. Dari dua faktor utama tersebut membuat PJTV Bandung harus melakukan perubahan yang menggabungkan lima TV konvensional milik Jawa Pos dengan coverage area yang lebih luas serta perubahan dari segi segmentasi pasar yang berbeda dari sebelumnya. Ada perubahan segmentasi antara PJTV Bandung dengan SKTV. PJTV Bandung memiliki segmentasi penonton lebih diutamakan pada anak muda, dengan konten urban. Sedangkan SKTV memilih segmentasi untuk dewasa, dengan konten sub-urban.

Banyak TV lokal yang ada di Bandung, namun tak semua mampu bertahan hingga saat ini. PJTV Bandung sendiri mampu mengudara lebih dari 13 tahun lamanya. PJTV juga saat itu memiliki kompetitor sesama TV lokal yang ada di Bandung. Kompetisi antar TV lokal tidak selalu berkaitan dengan positioning yang sama. Adapun kompetitor head to head dari PJTV Bandung adalah Bandung TV dan AK TV. Dengan rebranding PJTV menjadi SKTV juga membuat kompetisi menjadi semakin luas karena adanya penggabungan dengan SMTV Sumedang, CB Chanel Cianjur, K TV Kuningan dan Jatiwangi TV Majalengka. Dengan repositioning yang terjadi dari PJTV menjadi SKTV juga membuat perubahan pada kompetitornya. Perluasan coverage area membuat kompetitor SKTV menjadi lebih banyak dibandingkan saat menjadi PJTV Bandung. Sub urban sendiri menjadi market yang banyak ditinggalkan, namun PJTV Bandung melihat hal tersebut sebagai peluang untuk melakukan deferensiasi dengan TV lain. Dengan nama SKTV, brand positioning yang dipilih adalah market sub urban sebanyak $65 \%$ dan urban sebanyak 35\%. Dengan brand positioning baru tersebut SKTV lebih fokus pada masyarakat sub urban yang ada di daerah Jawa Barat.

Cheryl Isen (2012) mengungkapkan 6 alasan untuk mereposisi suatu brand, yaitu: (1) Kompetitor sudah merebut positioning brand kita, (2) Positioning brand awal menjadi membingungkan, (3) Perusahaan beruansa baru dengan keunggulan kompetitif yang eksklusif, (4) Adanya perubahan strategi perusahaan dalam lini bisnis seperti akuisisi atau pengembagan dengan target market baru, (5) Kompetitor berusaha mengubah permainan, perubahan tren tidak bisa dihindari, (6) Adanya perubahan yang signifikan pada struktur perusahaan (Isen, 2010). Dari 6 alasan tersebut yang menjasi alasan SKTV melakukan rebranding adalah brand positioning awal menjadi membingungkan, dimana program- 
program hiburan dan life style PJTV Bandung ditujukan untuk anak muda di kota Bandung tapi target audience tersebut berbeda dengan keadaan dilapangan. Dari hasil Ac Nielsen yang dimiliki PJTV Bandung diketahui bahwa pemirsa sesungguhnya dari PJTV Bandung adalah masyarakat yang berada di derah pinggiran kota Bandung. Selain itu, PJTV Bandung juga mengembangkan strategi perusahaan dalam target market baru dari yang sebelumnya dimilik. Jika awalnya PJTV Bandung memiliki market urban, saat melakukan proses rebranding menjadi SKTV market urban tersebut berubah menjadi sub urban karena adanya peluang dari target market tersebut yang baru disadari oleh tim kreatif PJTV Bandung menjadi SKTV.

SKTV ingin mem-branding dirinya sebaga TV sunda dengan pendekatan budaya yang kekinian sehingga kebudayaan yang mulai ditinggalkan memiliki nilai kembali dimata masyarakat. Hal tersebut seperti yang diungkapkan Scott Bedburry, branding adalah tentang membawa sesuatu yang biasa dan mengangkatnya dengan cara-cara yang membuatnya menjadi lebih berharga dan bernilai (Kotler \& Pfoertsch, 2008). Budaya kedaerahan yang mulai tergantikan oleh kebudayaan asing justru SKTV angkat agar menjadi lebih berharga dan bernilai.
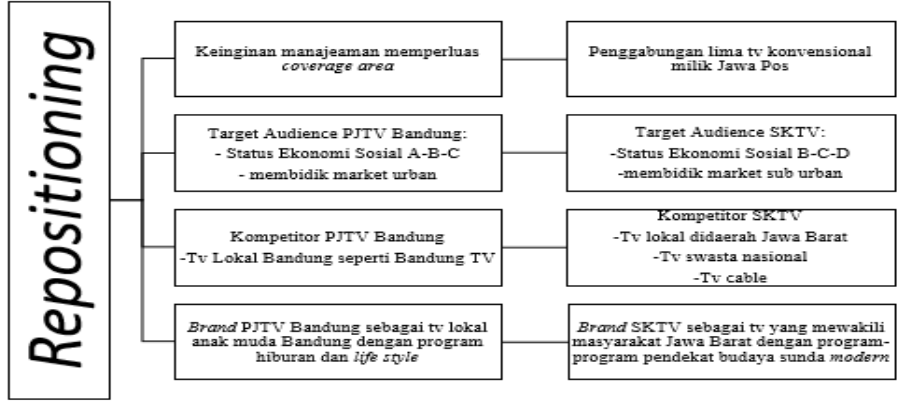

Sumber: Hasil Penelitian

\section{Gambar 1. Proses Repositioning PJTV Bandung Menjadi SKTV}

Renaming merupakan tahap selanjutnya dari proses perencanaan corporate rebranding. Pada tahap ini sebuah perusahaan harus memberikan informasi kepada seluruh stakeholder bahwa perusahaan tersebut melakukan perubahan strategi, fokus, atau perubahan struktur kepemilikan dari perusahaan. Salah satu cara yang dilakukan adalah dengan melakukan perubahan nama dari brand lama PJTV Bandung menjadi SKTV. Melihat fenomena persaingan yang semakin ketat, PJTV akhirnya mengambil keputusan untuk mengganti segmen market urban menjadi sub urban dengan sentuhan budaya sunda yang kekinian. Berdiri selama lebih dari 13 tahun, PJTV telah mengalami beberapa kali pergantian identitas perusahaan termasuk perubahan nama dan juga logo. Sejak pertama kali diluncurkan pada Maret 2005, PJTV merupakan singakatan dari Padjadjaran TV. Selanjutnya, pada tanggal 15 April 2010 mengalami pergantian nama menjadi Parijz van Java TV dengan singkatan nama tetap PJTV. Perubahan yang cukup signifikan terjadi pada tanggal 08 September 2017, PJTV Bandung bergabung dengan empat televisi konvensional milik Jawa Pos dan 
berganti nama menjadi Sunda Kiwari TV (SKTV).

Pemilihan nama menjadi salah satu hal penting yang harus di pikirkan oleh perusahaan ketika akan melakukan corporate rebranding. Nama dapat menjadi media bagi perusahaan untuk memberitahu kepada stakeholder bahwa perusahaan memiliki identitas baru yang diharapkan dapat diterima oleh semua pihak terkait. Pemilihan nama harus dilakukan dengan hati-hati dengan berbagai pertimbangann didalamnya. Selain pertimbangan mengenai nama yang mewakili Jawa Barat, nama tersebut juga harus memiliki pendekatan kultur sunda namun dengan sentuhan kekinian. Bahasa sunda sehari-hari digunakan agar lebih mudah diterima masyarakat. Setelah serangkain pemilihan nama, akhirnya tercetuslah nama Sunda Kiwari TV atau SKTV. Nama Sunda Kiwari dipilih karena dianggap mampu mewakili Jawa Barat dengan memunculkan kultur sunda kontenporer yang lebih mudah diterima oleh masyarakat.

Dalam jurnal Muzellec, et. al. (2003) klasifikasi renaming terbagi menjadi tiga bagian yaitu: (1) Nama deskriptif, (2) Nama asosiatif atau sugestif, (3) Berdiri sendiri, nama abstraksi, atau diciptakan (Muzellec et al., 2003). Sunda Kiwari Televisi atau SKTV termasuk dalam nama deskriptif karena Sunda Kiwari Televisi menyampaikan dengan jelas bahwa perusahaan tersebut bergerak pada bidang industri pertelevisian. Nama SKTV sendiri ingin menampilkan diri sebagai TV yang memiliki nilai pendekatan kultur Sunda modern.
Tidak bisa dipungkiri bahwa pemilihan nama SKTV berdasarkan pada penempatan nama pada daerah Jawa Barat saja, tidak secara nasional.

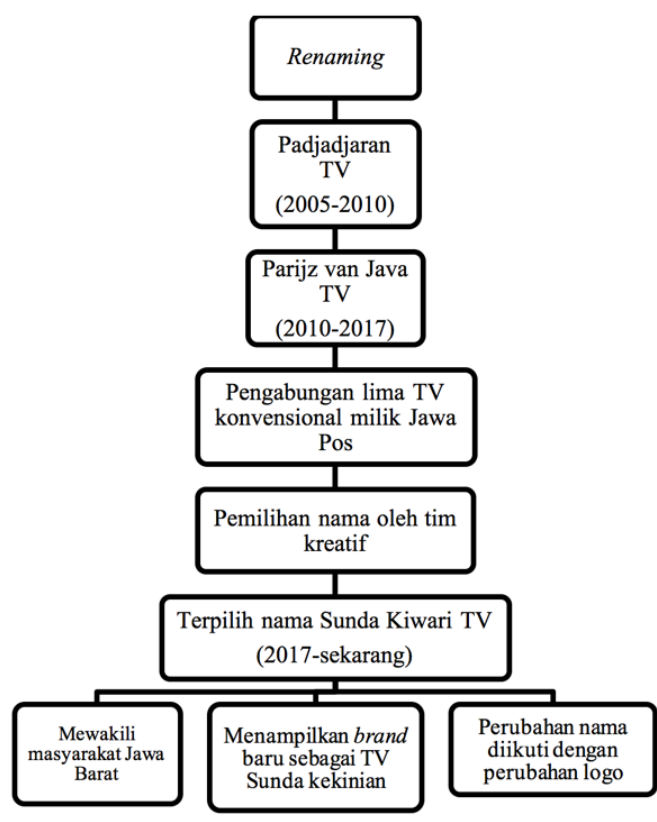

Sumber: Hasil Penelitian

Gambar 2. Proses Renaming PJTV Bandung Menjadi SKTV

Redesigning ini merupan bentuk perusahaan menampilkan dirinya kepada stakeholder-nya. Redesigning menggambarkan nilai-nilai suatu oraganisasi, bisnis, dan juga karakteristiknya. Hal yang biasa diperhatikan dalam redesigning antara lain dari pemilihan nama, logo, warna, jenis font, dan juga slogan. Penerapan logo sendiri biasanya ada di alat tulis, barang cetakan, iklan, situs web, kendaraan, bangunan, interior, dan pakaian perusahaan. Redesigning fokus pada perubahan estetika brand dan elemen tangible seperti logo, jingle, iklan atau elemen visual lain yang mencitrakan posisi dari suatu brand. Redesigning yang dilakukan PJTV Bandung menjadi SKTV 
meliputi berbagai elemen seperti logo, tampilan website, tampilan media sosial, dan lain-lain.

Setelah menemukan nama yang tepat, maka selanjutnya di buat desain logo baru yang sesuai dengan nama SKTV. Makna logo menjadi salah satu hal yang diperhatikan oleh tim kreatif ketika membuat desain baru. Warna, bentuk, dan font disesuaikan dengan karakter SKTV sebagai TV sunda kekinian yang mewakili masyarakat Jawa Barat. Selain warna dominan hijau tosca, warna lain yang digunakan untuk logo SKTV adalah kuning, putih dan biru. Warna-warna tersebut mewakili keberagaman yang dimiliki oleh masyarakat Jawa Barat. Warna hijau tosca merupakan warna hasil percampuran warna biru dan kuning. Warna hijau tosca tersebut mewakili suasana pedesaan di daerah Jawa Barat. Warna tersebut juga mewakili kesegaran. Warna kuning melambangkan senja atau masa lampau. Warna biru menggambarkan pagi hari yang mewakili semangat, muda dan kreatif. Warna biru juga melambangkan transisi dari PJTV Bandung menjadi SKTV. Secara tidak langsung penggunaan warna biru tersebut digunakan untuk memberi tahu kepada pemirsa bahwa PJTV tidak hilang tapi telah melakukan rebranding menjadi SKTV. Warna putih melambangkan niat suci untuk mengabdikan diri untuk kemajuan Jawa Barat.

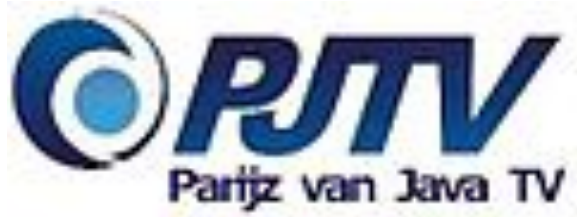

Sumber: https://images.google.com Gambar 3. Logo PJTV sebelum rebranding

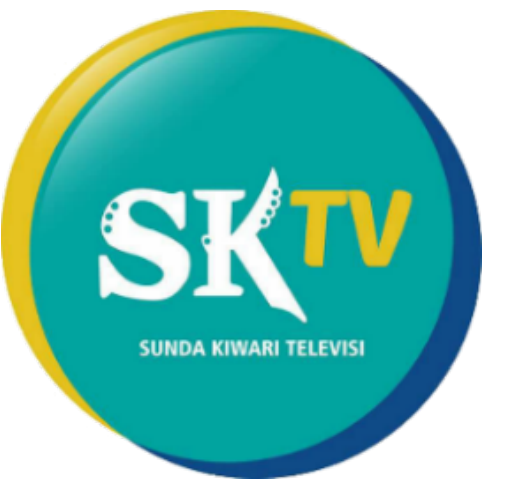

Sumber: dok.SKTV Gambar 4. Logo SKTV

Pemilihan bentuk yang digunakan pun sangat diperhatikan. Dalam logo SKTV terdapat penggunaan tulisan SKTV, kujang pada huruf K dan juga lingkaran. Tulisan SK ditulis dengan huruf kapital melambangkan kestabilan dan konsistensi. Kata TV dalam logo SKTV dipisahkan menggambarkan bahwa SKTV merupakan perusahaan yang bergerak dibidang pertelevisian. Bentuk kujang pada huruf $\mathrm{K}$ melambangkan bahwa SKTV merupakan televisi sunda yang merepresentasikan Jawa Barat. Bentuk bulatan yang tidak memiliki sudut menggambarkan SKTV sebagai industri kreatif yang tidak memiliki batas kreatifitas. Bentuk dua lingkaran yang saling menyatu menggambarkan perpaduan masa lampau dan masa sekarang sesuai dengan visi misi SKTV yang mengusung konsep sunda modern. Selain itu, lingkaran itu juga mewakili kekuatan penuh serta cangkupan siaran dari SKTV, yaitu Jawa Barat. Bentuk lingkaran juga diibaratkan seperti bulan yang mengalami pergeseran seperti yang terjadi pada SKTV sekarang ini.

Penempatan logo hasil redesigning menjadi salah satu kunci untuk dapat mempermudah karyawan, client, maupun target 
audiens lebih cepat mengenal SKTV. Dari pendapat Muzellec, et. al. (2003) menyebutkan:

"The redesigning is carried through on all elements of the organization's livery such as stationery, brochures, advertisement, annual report, offices, and delivery trucks, which are the visible manifestations of the company's desired position," (Muzellec et al., 2003).

Penempatan logo SKTV juga menjadi perhatian dari tim kreatif. Dengan penempatan logo yang baik bisa membuat orang-orang yang melihatnya mudah mengenali SKTV. Penempatan logo SKTV dilakukan di Kantor SKTV, alat kantor, kendaraan operasional, serta tampilan siarannya. Penempatan logo SKTV diterapkan secara on air dan off air. Penempatan logo secara on air terdiri penempatan program dan non program. Ukuran logo dalam penempatannya secara on air sekitas 23 pixel. Ukuran tersebut dipilih karena dianggap jelas terlihat dari layar televisi dan tidak menghalangi tayangan yang disiarkan. Lalu penempatan logo secara off air terdiri dari penempatan logo pada FO, media order, kop surat, seragam kerja, id card, business card dan request form. Penampilan on air lebih banyak berubah, terutama setting studio. Beberapa setting studio disesuaikan dengan warna SKTV yang di dominasi warna hijau toska, biru dan kuning. Perubahan setting studio ini juga untuk membawa semangat baru dari setiap tayangan program SKTV.
Selain perubahan tersebut, program dan konten acara di SKTV juga mengalami perubahan walaupun tidak seluruhnya. Ada program-program PJTV Bandung yang masih dipertahankan dan disiarkan di SKTV. Pendekatan bahasa dan budaya kesundaaan terus dimunculkan dalam program siaran SKTV. Beberapa program-program baru pun dimunculkan sebagai program unggulan dari SKTV. Beberapa program yang dipertahankan seperti Icip-Icip dan juga Bandung Magazine yang berganti nama menjadi Camperenik.

Restructuring biasa terjadi dalam sebuah perusahaan, begitupun yang dialami oleh PJTV Bandung saat memelakukan rebranding menjadi SKTV. Susunan struktur organisasi saat ini terdiri dari Direktur, Dept. News, Dept. Produksi, Dept. Program, Dept. Teknik, Dept. Marketing dan gabungan Dept. HRD dan Finance. Secara susunan struktur organisasi tidak terjadi perubahan yang berarti, penambahan karyawan merupakan hal biasa yang terjadi. Masih banyak karyawan dari sebelum rebranding yang bertahan. Baik karyawan lama maupun baru dapat berbaur dengan baik. Peran para Departemen Head yang ada di SKTV penting karena Direktur SKTV tidak selalu ada ditempat. Para department head tersebut akan saling berkordinasi untuk mengatur kegiatan yang berada dibawah pengawsan mereka. Perubahan system dalam pengelolaan kinerja perusahaan masih bisa terjadi mengingat perubahan dari PJTV Bandung menjadi SKTV ini baru berlangsung beberapa bulan. 
Walaupun SKTV merupakan gabungan lima TV konvensional milik Jawa Pos, namun untuk biro SKTV memiliki manajemen yang berbeda sehingga beberapa kegitan dilakukan secara mandiri. Perubahan yang terasa pada biro-biro tersebut adalah pada posisi Direktur kini berubah menjadi Kepala Biro. Selain itu perubahan yang terasa adalah mulai banyaknya program in house yang dibuat SKTV. Dengan adanya program in house ini maka jam kerja karyawan SKTV menjadi lebih lama dari sebelumnya. PJTV Bandung dulu lebih banyak menanyangkan blocking time pada siarannya. Blocking time yang disiarkan berupa iklan home shopping. Kini, penayangan bloking time hanya sekitar 6 jam saja. Tugas dari pos produksi bertambah dengan banyaknya program in house yang dibuat oleh SKTV.

Setelah membahas mengenai analiasis dan perencanaan, selanjutnya adalah pembahasan mengenai proses implementasi corporate rebranding PJTV Bandung menjadi SKTV. Proses implementasi ini terbagi menjadi dua, yaitu relaunching internal dan relaunching eksternal. Proses relaunching menjadi penentuan bagaimana stakeholder internal melihat brand baru mereka. Hal ini sama pentingnya dengan proses relaunching kepada pihak eksternal, hanya caranya saja yang berbeda. Untuk relaunching terhadap pihak internal ini bisa berupa brosur internal, surat kabar, pertemuan tahunan, lokakarya atau intranet. Prosess relaunching sendiri dapat disesuaikan dengan kebutuhan dari perusahaan itu sendiri. Proses relaunching kepada pihak internal SKTV termasuk publikasi secara cetak serta beberapa kegiatan untuk karyawan.

Proses relaunching tersebut juga memerlukan waktu yang tidak sebentar hingga akhirnya bisa terlaksana. Satu tahun waktu yang dibutuhkan untuk memilih nama, segmentasi, program, dan tools apa yang akan digunakan dalam perubahan PJTV Bandung menjadi SKTV. Dengan waktu yang cukup panjang tersebut membuat karyawan mulai terbangun jiwa baru dengan sudut pandang sebagai SKTV.

Muzellec, et. al. (2003) menjelaskan relaunching sebagai berikut:

"For the internal stakeholder, the new brand can be introduced through internal brochure or newspaper, at external stakeholders through press release and advertising to create awareness around the new name and to facilitate the adoption of the new name by the various stakeholders," (Muzellec et al., 2003).

Berdasarkan penjelasan di atas, publikasi terhadap pihak internal dilakukan dengan brosur atau koran internal, annual meeting, atau dengan workshop dan intranet. Dalam proses rebranding PJTV Bandung menjadi SKTV, publikasi terhadap pihak internal pun dilakukan. Poses relaunching internal lebih ditekankan pada seluruh karyawan yang ada. Hal itu dilakukan agar ketika relaunching eksternal dilakukan maka seluruh karyawan telah memiliki semangat baru sebagai SKTV. Pengenalan ini tidak mengalami hambatan yang berarti karena baik secara langsung atau tidak, seluruh karyawan terlibat 
dalam proses rebranding ini. Karyawan SKTV juga terlibat dalam berbagai meeting yang dilakukan.

Untuk pengenalan brand baru kepada pihak eksternal bisa dilakukan melalui siaran pers dan iklan. Relaunching bertujuan untuk publikasi brand baru serta sebagai penentuan persepsi publik kepada brand baru yang dimiliki. Hal ini cukup sulit dilakukan karena kemungkinan besar bahwa pihak eksternal lebih mengenal brand PJTV Bandung ketimbang SKTV. Selain itu, pihak yang awalnya bekerja sama dengan PJTV Bandung mungkin akan mengalami kebingungan dengan adanya rebranding ini jika tidak diberikan informasi yang memadai. Proses relauncing SKTV ini dipikirkan dengan baik sebelum, saat, dan sesudahnya akan seperti apa. Proses untuk relaunching terhadap pihak eksternal ini tidaklah sebentar hinga akhirnya terlaksana acara seremonial dan berbagai acara lainnya untuk mendukung pengenalan brand baru SKTV.

Fandi Tjiptono, Gregorius Chandra, dan Dadi Adrian menjelaskan penggabungan sejumlah strategi pokok dalam proses rebranding (Tjiptono et al., 2008) yaitu, Phase In/ Phase out strategy, Umbrella branding strategy, Translucent warning strategy, Sudden eradication strategy, Counter-takeover strategy, dan Retrobranding strategy. Untuk media sosial dan website juga dimanfaatkan oleh SKTV. Media sosial yang dimiliki SKTV antara lain Facebook, Twitter, Instagram, dan YouTube. Tampilan media sosial dan website mulai berubah. Untuk Instagram sendiri melakukan penghapusan posting-an lama dan mulai membuat pemberitahuan bahwa akan ada perubahan dari PJTV Bandung menjadi SKTV. SKTV juga mengunggah beberapa teaser mengenai akan adanya masyarakat baru, masyarakat sunda kiwari. Strategi yang dilakukan SKTV adalah translucent warning strategy, yaitu mengingatkan para pelanggan sebelum dan setelah perubahan nama merek aktual (Tjiptono et al., 2008). Hal tersebut dilakukan SKTV melalui media sosial yang dimilikinya. Strategi tersebut terlihat saat PJTV Bandung kala itu melakukan promosi di media sosial, radio, koran dan TV. Setelah melakukan serangkaian promosi tersebut, pada tanggal 8 September 2017 PJTV Bandung melakukan relaunching menjadi SKTV.

Sebelum berlangsungnya acara seremonial relaunching SKTV, terlebih dahulu dilakukan promosi-promosi baik di TV, radio maupun koran. Tim marketing pun mengirimkan surat kepada client dan melakukan company visit untuk memberitahukan adanya perubahan PJTV Bandung menjadi SKTV. Kegiatan yang dilakukan untuk melakukan pendekatan kepada masyarakat adalah dengan mengadakan roadshow. Setelah melakukan rebranding, SKTV masih mengalami kesulitan ketika akan melakukan liputan sehingga harus menjelaskan bahwa SKTV merupakan hasil rebranding dari PJTV Bandung.

Relaunching SKTV secara seremonial dilakukan dengan mengadakan talkshow yang 
mengangkat tema budaya sunda dalam perspektif Indonesia. Dalam acara tersebut turut mengundang pemerintah daerah, termasuk kepala daerah untuk mensukseskan acara. SKTV juga berupaya unuk memperbanyak kegiatan off air. Selain itu juga ada programprogram lain yang disiapkan untuk mendukung kelancaran dari proses relaunching tersebut. Program unggulan yang sudah berjalan adalah Warta Kiwari.

Beberapa pihak yang diundang dalam acara relaunching SKTV antara lain clientclient, pemerintah, KPID, dan AC Nielsen. Pihak-pihak tersebut diundang untuk hadir dalam acara relaunching yang berupa dialog budaya. Relaunching ini cukup berbeda karena biasanya relaunching yang dilakukan stasiun TV lebih banyak berupa hiburan seperti konser musik atau awarding. Relaunching ynag dilakukan SKTV ini bertujuan untuk melihat bagaimana pandangan dari para tamu undangan tentang budaya yang ada saat ini.

Selain program-program siaran ada pula kegiatan off air yang dilakukan sebagai upaya untuk memperkenalkan brand baru SKTV kepada publik eksternalnya. Kegiatan off air yang sudah dilakukan adalah kerjasama dengan KPU Kota Bandung seperti mengadakan debat pilkada. Selanjutnya ada event Kampung Hidroponik yang disponsori oleh Pipa Power, merupakan kegiatan bercocok tanam dengan menggunakan hidoponik yang menghasilkan tanaman sayur organik yang lebih sehat.

Pasca relaunching, SKTV juga menyiapkan program-program baik on air maupun off air. Format acara SKTV terdiri dari news, feature, 
dan hiburan yang menggunakan bahasa Indonesia dan bahasa sunda. Komposisi program SKTV terdiri dari entertainment 30\%, news $25 \%$, blocking time $30 \%$, talkshow $10 \%$ dan religi 5\%. SKTV mebidik market sub urban sebanyak $65 \%$ dan urban sebanyak $35 \%$. Dengan potential viewers SKTV sebanyak 18.790.860 jiwa, tentu SKTV harus menyiapkan program terbaiknya. Program unggulan yang dihadirkan antara lain Warta Kiwari, Bincang Kiwari dan Bobotoh Persib. Ketiga program tersebut memiliki rating yang cukup tinggi. Selain itu juga ada rancangan program yang sudah disiapkan seperti Gondang Kiwari.

Relaunching terhadap pihak eksternal merupakan tindakan dan pengkomunikasian bahwa PJTV Bandung telah melakukan rebranding menjadi SKTV. Dalam hal ini, tidak semua karyawan terlibat dalam pelaksanaan proses relaunching terhadap pihak eksternal agar kegiatan berjalan lebih maksimal. Dari hasil diskusi yang dilakukan akhirnya disepakati untuk melakukan relaunching eksternal dengan mengadakan acara talkshow dengan tema budaya. Tokoh - tokoh Jawa Barat, client, dan pemerintah daerah pun turut hadir dalam acara relaunching ini. Relaunching ini tidak hanya ditujukan untuk memberitahukan bahwa PJTV Bandung telah melakukan rebranding menjadi SKTV, tetapi juga sebagai ajang diskusi mengenai bagaimanan budaya sunda saat ini.

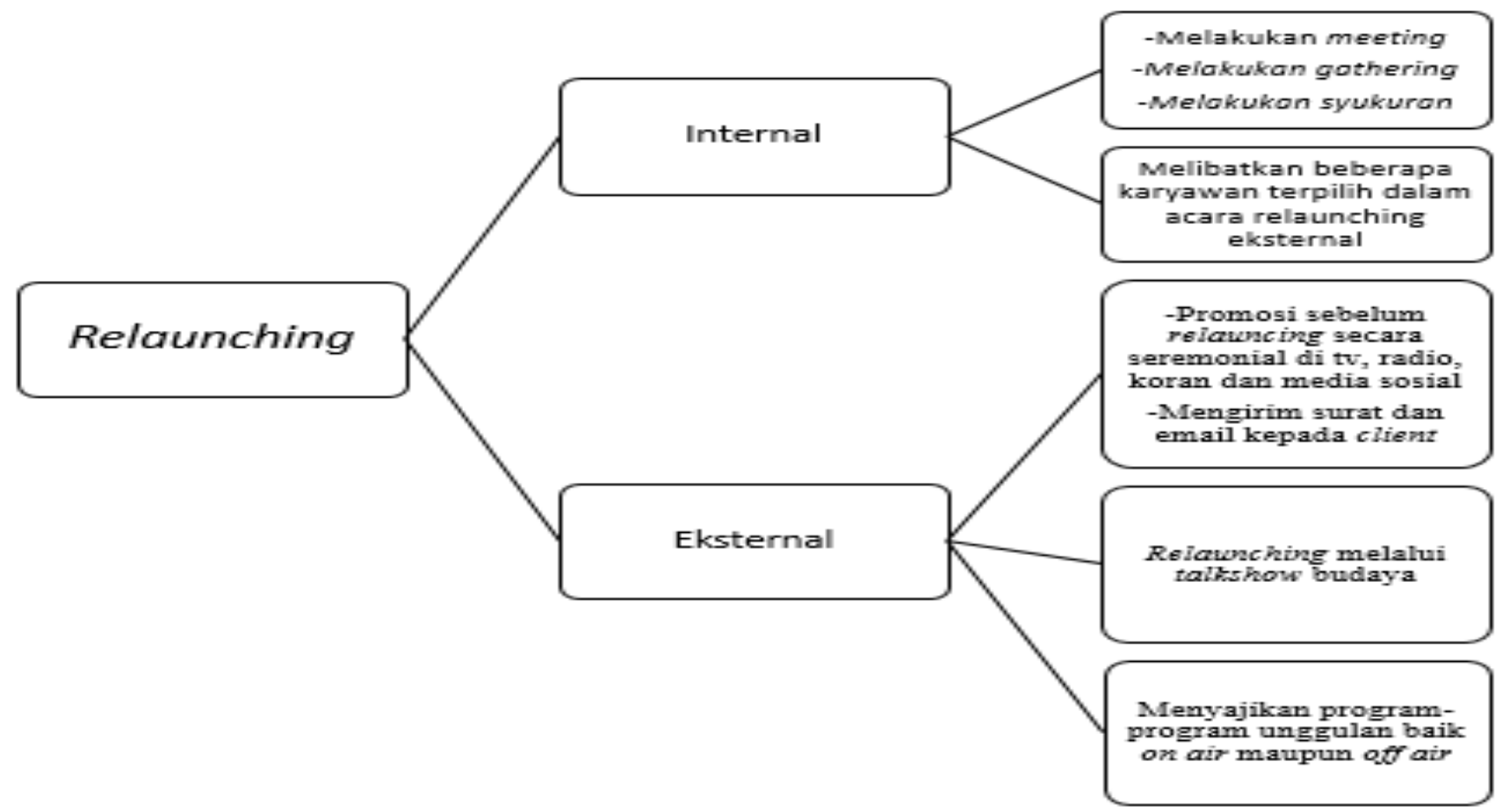

Sumber: Hasil penelitian

Gambar 5. Relaunching internal dan eksternal corporate rebranding PJTV Bandung menjadi SKTV

Tahap terakhir adalah evaluasi. Evalusi dilakukan sebagai pengukur keberhasilan atau kegagalan dari proses rebranding yang dilakukan. Pengukuran keberhasilan dalam 
sebuah evaluasi harus disesuaikan dengan tujuan awal dari rebranding itu sendiri. Evaluasi sebaiknya dilakukan secara bertahap serta mencangkup semua fase proses yang ada. Evalusi juga dilakukan oleh SKTV secara rutin. Evaluasi yang dilakukan secara rutin seperti evaluasi setiap selesai program on air, dan rapat yang dilakukan setiap seminggu sekali. Evaluasi yang dilakukan SKTV lebih bersifat evaluasi secara internal. Sebulan setelah relaunching, evaluasi sudah mulai dilakukan.

Evaluasi program dilakukan dengan melihat AC Nielsen untuk melihat bagaimana presentasi pemirsa yang menonton program SKTV. Adanya hasil AC Nielsen tersebut dapat menjadi bahan pertimbangan apakah program tersebut akan dipertahankan atau tidak. Dari hasil AC Nielsen tersebut program SKTV yang memiliki rating cukup baik adalah Warta Kiwari, Bobotoh Persib, dan Bincang Kiwari. SKTV dalam membuat program juga melibatkan komunitas didalanya karena SKTV tidak hanya ingin menampilkan program yang bagus namun program tersebut juga harus berdampak baik bagi masyarakat. Hal tersebuta juga membantu dalam memperkenalkan SKTV pada masyarakat.

\section{Proses rebranding SKTV sudah} berlangsung beberapa bulan, namun untuk evaluasi mengenai tanggapan pemirsa mengenai rebranding belum dilakukan. Hal tersbut mengakibatkan belum diketahuinya tanggapan apakah brand SKTV sudah melekat pada pemirsanya atau belum. Tahap evaluasi yang dilakukan oleh SKTV adalah evaluasi yang dilakukan setelah meeting rutin dilakukan.
Untuk program acara live, evaluasi dilkukan selesai acara disiarkan. Hasil AC Nielsen juga digunakan sebagai evaluasi program untuk mengetahui seberapa banyak jumlah penonton pada setiap program yang disiarkan. Untuk evaluasi terhadap tanggapan masyarakat mengenai perubahan PJTV Bandung menjadi SKTV belum dilakukan karena rebranding ini baru berjalan belum genap satu tahun.

\section{SIMPULAN}

Tahap analisis yang dilakukan cukup baik, dimana faktor internal pendorong terjadinya rebranding adalah keinginan manajemen untuk membuat satu nama televisi bagi satu Provinsi dan faktor eksternal pendorong terjadinya rebranding adalah adanya perbedaan antara target audience dengan keyataan dilapangan. Sebagai televisi lokal, SKTV juga sudah mentaati Undang-undang Nomor 23 Tahun 2002 tentang Penyiaran.

Tahap perencanaan terdiri dari repositioning, renaming, redesigning, dan restructuring. Tahap Pada tahap ini sudah berjalan cukup baik. SKTV mengganti brand positioning menjadi market sub urban sebanyak $65 \%$ dengan target audience yang lebih spesifik. Renaming yang dilakukan adalah mengubah nama PJTV Bandung menjadi SKTV. Redesigning terjadi pada hampir semua elemen visual dilakukan perubahan. SKTV berhasil membuat logo yang memiliki filosofi yang berkaitan dengan makna nama SKTV. Aplikasi logo dilakukan baik secara on air maupun off air. Redesigning juga terjadi pada program dan konten SKTV yang menyesuaikan dengan 
semanangat baru sebagai televisi sunda modern. Restructuring, tidak ada perubahan dalam susunan struktur organisasi secara signifikan.

Tahap implementasi terbagi menjadi dua, yaitu relaunching kepada pihak internal dan relaunching terhadap pihak eksternal sudah dilakukan dengan baik. Relaunching kepada pihak internal, SKTV dilakukan dengan kegiatan syukuran dan gathering. Relaunching terhadap pihak eksternal, SKTV melakukan banyak kegiatan seperti promosi, mengirim surat atau email kepada client, melakukan company visit, mengadakan launching eksternal berupa talkshow, serta menghadirkan programprogram unggulan.

\section{DAFTAR PUSTAKA}

Ahonen, M. (2008). Corporate Re-Branding Proses: A Preliminary Theoritical Framework. In Proceeding of the Conference on Corporate Comunication 2008, 6th-9th. Wroxton.

Effendy, H. (2008). Industri Pertelevisian Indonesia. Jakarta: Erlangga.

Isen, C. (2010). Brand Repositioning: When Does Your Business Need It. Puget Sound: Business Journal.
Kotler, P., \& Pfoertsch, W. (2008). B2B Brand Management. Jakarta: BIP.

Moleong, L. (2007). Metodologi Penelitian Kualitatif. Bandung: Remaja Rosdakarya. Muzellec, L., Doogan, M., \& Lambkin, M. (2003). Corporate Rebranding-An Explanatory Review. Irish Marketing Review, 16.

Rakhmat, J. (2012). Metode Penelitian Komunikasi: Dilengkapi Contoh Analisis Statistik. Bandung: Remaja Rosdakarya.

Salim, A. (2006). Teori Dan Paradigma: Penelitian Sosial. Yogyakarta: Tiara Wacana.

Sugiyono. (2010). Metode Penelitian Kuantitatif, Kualitatif, dan $R \& D$. Bandung: Alfabeta.

Tjiptono, F., Chandra, G., \& Adrian, D. (2008). Pemasaran Strategik. Yogyakarta: ANDI.

\section{Sumber Lainnya:}

Company Profile Internal SKTV

Logo PJTV (24, June 2018). Diakses dari: https://images.google.com 